\title{
EAl Endorsed Transactions

\section{Study on Evolutionary Approaches for Improving the Energy Efficiency of Wireless Sensor Networks Applications}

D. Lubin Balasubramanian ${ }^{1, *}$ and V. Govindasamy ${ }^{2}$

${ }^{1}$ Research Scholar, Department of Computer Science \& Engineering, Pondicherry Engineering College, Puducherry, India

${ }^{2}$ Associate Professor, Department of Information Technology, Pondicherry Engineering College, Puducherry, India

\begin{abstract}
One of the drastically increasing and tremendously demanding networks is the wireless sensor network, which provides an elastic platform where any user can design their sensor-based applications easily. Most of the WSN applications can be accommodated in the existing infrastructure or not require any predefined infrastructure. But it has a wide range of applications across the globe which further increases the complexity of the problems in it. Because WSN is a resourceconstrained kind of network where energy consumption is one of the major problems. Some of the problems were addressed by deterministic approaches discussed in earlier research works. In case of efficient routing of messages across the network dynamic programming is one of the deterministic approaches which addresses an efficient routing algorithm. But for a wide range of WSN deterministic algorithms are a time-consuming process. On the other hand, evolutionary algorithms are one such fast-growing domain in the past few decades which addresses many of WSN problems. This paper is a comprehensive survey on the Application of Evolutionary Algorithms in Wireless Sensor Networks. A detailed description of the papers taken for the survey is tabulated in this paper.
\end{abstract}

Keywords: Wireless Sensor Networks, Evolutionary Algorithms, Solution Representation, Binary, Discrete.

Received on 30 September 2019, accepted on 15 October 2019, published on 30 October 2019

Copyright (C) 2019 D. Lubin Balasubramanian et al., licensed to EAI. This is an open access article distributed under the terms of the Creative Commons Attribution license, which permits unlimited use, distribution and reproduction in any medium so long as the original work is properly cited.

doi: 10.4108/eai.13-7-2018.164856

\section{Introduction}

One of the major portions of recent real time industrial applications is developed on WSN [1]. It is increasing continuously for utilizing the potential use of WSNs' applications such as monitoring remote environment, disaster, healthcare, intelligence surveillance, biggest buildings and defence reconnaissance [2-3]. A typical WSN Various kinds of sensor nodes are used in different application [4-5] according to the application necessity. Sensors are called as nodes in the network, where all the nodes are deployed statically or dynamically in the environment according to the application's [6] requirement. In certain applications, the nodes used to monitor and record the data about the environment is called as target nodes and other nodes can collect the data from the target and transmit to the base station. In this scenario, considering the data transmission efficiency and network lifetime, different methods and routing protocols have been used. Most of the routing protocols used for energy efficient and energy balancing have been proposed in the earlier research works. Though according to the application design and requirement they have their own week points. Energy is considered as the main concern, since, WSNs are scattered spatially with individual sensor nodes to monitor and track the target objects and monitoring the environment. The set of all applications under wireless sensor networks is depicted in Figure-1 [6], and Table-1 describes the objectives of the applications.

*Corresponding author. Email: balu.daya@gmail.com 


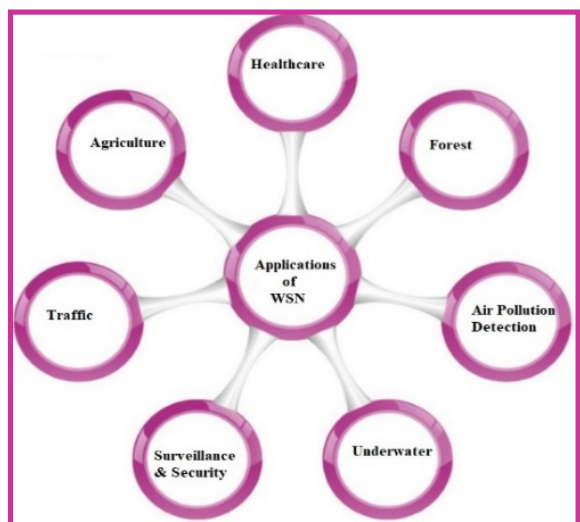

Figure 1. Applications of Wireless Sensor Networks

Comprises of a great number of lesser costs, multipurpose sensor node which has been deployed for various purposes. In general, all the sensors are small in size and restricted in power and inbuilt with micro-controllers and radio transceivers [7]. The set of all sensor nodes are used for external functions where it senses and transmit the environmental data [8]. Real life environmental circumstances are being sensed, recorded, transformed into logical data by the sensor nodes in WSN which are further transferred, processed and used by users for many purposes. The design and quality of the sensor nodes not static for all scenarios. It differs in terms of design, robustness, transmission power, channel bandwidth, durability, etc, [9-11]. For example, sensor nodes in marine region are different from those placed in underground. Marine region sensors are well equipped and modelled which can withstand against the strikes such as moistures, water proof, etc. On the other side, underground sensors should be equipped with high transmission power in order to overcome the encircled noisy region. Sensor nodes can be coined as self-defensive, since it transfers alive status periodically thus helps the receiver side clients to monitor its durability [12-15].

Table 1. WSN's Applications and Their Objectives

\begin{tabular}{|c|l|}
\hline $\begin{array}{c}\text { Applications } \\
\text { Agrisulture }\end{array}$ & $\begin{array}{l}\text { Objectives } \\
\text { pressure and also ensures an accurate } \\
\text { environment for the crop cultivation. }\end{array}$ \\
\hline $\begin{array}{c}\text { Environmental } \\
\text { Monitoring }\end{array}$ & $\begin{array}{l}\text { Senses all the environmental parameters } \\
\text { and to prevent calamities like gas leakage, } \\
\text { flood, forest fire etc. }\end{array}$ \\
\hline $\begin{array}{c}\text { Vehicle } \\
\text { Tracking }\end{array}$ & $\begin{array}{l}\text { Helps in preventing traffic congestion and } \\
\text { parking system and also the location of the } \\
\text { vehicle. }\end{array}$ \\
\hline $\begin{array}{c}\text { Health care } \\
\text { Monitoring }\end{array}$ & $\begin{array}{l}\text { Helps in the real time monitoring of the } \\
\text { physiological signals and prevents the risk } \\
\text { that may occur to its life. }\end{array}$ \\
\hline Smart Buildings & $\begin{array}{l}\text { Consumes low energy and provides home } \\
\text { and building security to an extent }\end{array}$ \\
\hline $\begin{array}{c}\text { Security and } \\
\text { Surveillance }\end{array}$ & $\begin{array}{l}\text { Helps in the early detection of the enemies } \\
\text { and vehicle tracking. }\end{array}$ \\
\hline Animal & $\begin{array}{l}\text { Monitors the animals by optimizing rearing } \\
\text { conditions and controlling animal's stress } \\
\text { level by monitoring the vibration and } \\
\text { movement }\end{array}$ \\
\hline
\end{tabular}

As the electronic devices decreases in size and cost, the usage of wireless sensor network has been elevated exponentially and it became to be a part of our day today life. Progress of WSN from the time of invention shown a tremendous growth in terms of power consumption, cost, magnitude, range, bandwidth. Several researches work [1618] have discussed about energy efficiency by reducing the energy consumption in various kinds of WSN applications. These advances of WSN makes it easier to be applicable in multipurpose environments. Basically, the network scenario of Wireless sensor network is Ad-Hoc in nature by which the establishment made it easier. Figure-2 describes different topologies of WSN, which helps to design the application structure [19].

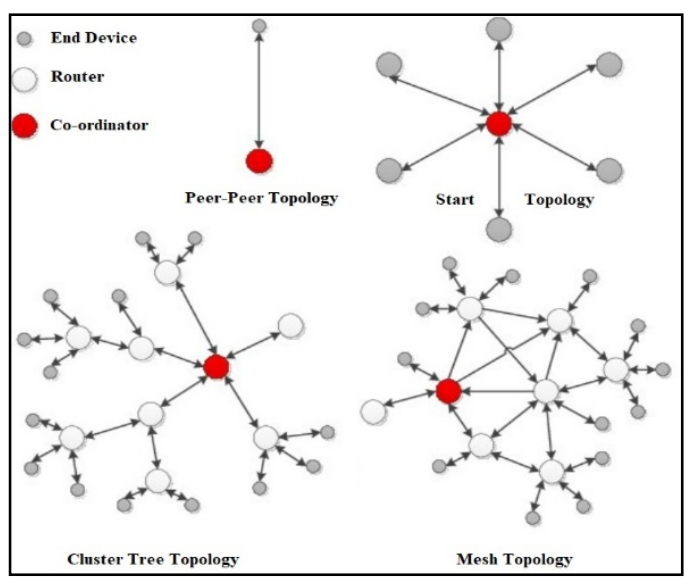

Figure 2. Topologies of Wireless Sensor Network

WSN have a wide range of application domains in recent decades. These includes temperature monitoring, humidity of air, water level, pressure level, safety monitoring of vehicles, monitoring the tunnels, monitoring healthcare unit, road safety surveillance, traffic reconnaissance, etc, 
[20]. As it is mentioned earlier, the sensor nodes deployed for the mentioned scenarios requires different design and quality factors. Due to wide range of application of WSN in urban regions, gets the attraction from researchers due to its complexity of data collision, data aggregation, etc [7]. Some of the major research-oriented topics in WSN are routing, node deployment, node localization, etc [21]. Searching for possible paths during data transformation is the preliminary stage of routing process. Later the process has been fine-tuned to find path with less traffic and also dynamic like avoiding run time collisions and much more. Exhaustive method searching for feasible routes are more time consuming for high dimensional networks with hundreds of sensor nodes [22]. Introduction of heuristics in WSN elevated the problem to be solved with less computational time when compared to exhaustive search. For solving multi-objective problems, heuristic search is inefficient in terms of computational complexity [23].

In past few decades, solving NP-hard problems using meta-heuristic algorithms which are inspired from nature plays a vital role in research. Meta-heuristic algorithms are stochastic in nature which can converge to global optimal solution using evolutionary process. That means the algorithm converge towards optimal solution in iterative and evolution basis.

\subsection{Motivation and Background}

This paper discussed about fundamentals of wireless sensor networks, applications, and methodologies for improving the energy efficiency and QoS of the WSN's applications. From various earlier recent research works, it comes to know that optimization, artificial intelligence, heuristic and metaheuristic approaches are better approaches can improve the network quality of service. Hence this paper motivated on discussion about meta-heuristic algorithms and various routing protocols proposed to improve the energy efficiency of WSN. Meta-heuristic algorithms are superior than other existing algorithms in terms of convergence towards optimal solutions within a reasonable period of time. Problems of WSN are being solved by EA algorithms with high reliability but at the same time with number of trials since the algorithms are non-deterministic. This paper gives a comprehensive description of WSN application domains and the impact of EA in WSN problems. Each application described in this paper contains a brief knowledge about the paper.

\subsection{Contribution of Survey Article}

The entire contribution of the paper is, discussing the introduction about WSN, applications of WSN and topology. From the introduction section, it is identified that the energy efficiency is one of the major problems and it needs to be rectified. In order to do that, various algorithms and routing protocols are used in the earlier research works. From the review of literature, it has been identified that EA algorithms are better for identifying the optimized elements such as nodes, route, data packets and other network configurations. Hence it presents detailed information about EA algorithms, and various routing protocols. Even though there are considerable numbers of survey on WSN applications and EA based applications and algorithms are presented, none of them are concerned with the mapping process such as solution representation. Since solution representation plays a key role in mapping EA with WSN problem it has to be pointed and sorted out. Once the solution representation is known then the corresponding problem can be easily mapped with EA based approach. This paper mainly focusses on the applications of WSN and a detailed survey on EA applications in optimizing WSN problems.

\subsection{Related Survey Articles}

In the year 2002, the authors in [24] presented a survey on wireless sensor network and its applications. In the year 2008, the authors in [25] presented a paper on wireless sensor networks and its protocols. Adnan, et al [26] in the year 2013 presented an enhanced survey on Wireless sensor networks and its applications. The key role of this paper is the application of evolutionary algorithms in the sub domains of wireless sensor networks. Three major algorithms are taken for the survey namely Genetic Algorithm, Ant Colony Optimization and Particle Swarm Optimization. The survey comprises of the papers that are published till 2013. Our survey holds the methodologies handled to outbreak the problems encountered in wireless sensor networks using Evolutionary algorithms after 2013.

\section{Applications of WSN}

The surveillance or monitoring capability of sensors in WSN leads a network to be deployed in numerous environments in order to reduce the utilization of human resources and cost of implementation. Before the invention of WSN, environmental changes are monitored either by human or wired networks. This tends to be cost expensive and consumes human resource power. Since WSN holds the property of wireless communication, deploying wireless sensors elevated the practice of WSN for monitoring. This approach reduces the establishment cost of network. In past two decades WSN has been applied in a vast number of domains for efficient sensing of surroundings. In the following section the author discussed on WSN applications of major domains. This abstract survey consists of domain introduction, WSN importance on it and research contributions over that domain from the perspective of WSN.

\subsection{Application over Power Distribution System}

Power Distribution System (PDS) is the process of allocating the incoming power to respective areas in a 
region. Due to glitches, those systems often get encumbered which leads to power failure and immense blackouts. Ensuring the stability in power distribution requires frequent monitor over the distribution and appropriate action needs to be carried out when any malfunction occurs. The sensor nodes in WSN applied on this domain due to low cost of establishment for data communication. This data consists of the environmental changes in PDS, reports to sink node where the appropriate decision will be taken. From this viewpoint, author proposed many research articles addressing different scenarios of PDS which are as follows. Lim, et al [27] proposed Power quality monitoring system using WSN for keep tracking on the voltage and frequency differences. ZigBee technology by Cao, et al [28] and EMMNet network by Lin, et al [29] models are proposed for automatic meter reading remotely. Ahmad, et al [30] implemented WSN for monitoring the growth of vegetation over those overhead conductors with the help of cameras. Yang, et al [31] in the year 2007 presented a detailed survey on self-powered sensor nodes deployed in WSN for monitoring thermal rate of conductors.

\subsection{Applications over Transportation}

In the domain of transportation, WSN plays a key role in assistance to the driver for safety purposes. Initially WSN applications on transports reported for safety monitoring but later this turned into luxury and sophistication for vendors which makes nowadays as driverless vehicles. In year 2004, Nadeem, et al [32] proposed a model for efficient traffic monitoring using WSN named as TrafficView. In this a central system tracks every vehicle in road in terms of speed, position, etc. With this TrafficView as a base, Dashtinezhad, et al [33] proposed a navigation mechanism which keeps on monitoring the environmental changes. Curiac, et al [34] proposed a WSN which models traffic light control system. And also, an efficient traffic control has been evolved by designing the vehicle flow based on decision making process. Ferreira, et al [35] proposed a traffic control model by disseminating the data of traffic to the vehicles directly by using road side units. WSN has been the underlying base for the emergence of VANET. Hence some of the protocols, location monitoring system of WSN are applicable in VANET and a detailed comprehensive study has been given in Bruno, et al [36]. Rahim, et al [37] proposed a framework to reduce the load in the transmission path and addressed the limitations in bandwidth while transmitting multimedia data through the network. Eun Yoo, et al [38] proposed TSN (Telematics Sensor Network) which evaluates the performance of vehicles on road. Ceriotti, et al [39] proposed a model for controlling light system in tunnels. It monitors the light effects of tunnel for appropriate adjustment of light illumination by which a series of accidents or pileups can be avoided. Tang, et al [40] proposed an efficient intelligent based parking system which comprises of tracking capability of free spaces in a parking lot. The proposed method works in an event driven manner in order to minimize energy consumption of vehicles. Stajano, et al [41] in the year 2010, proposed WSN based monitoring system for efficiently tracking three different passages namely human suspension bridge, Ferriby Road bridge and Jubilee railway tunnel. Many survey papers also were published during that era which consolidates the deployment of WSN for achieving efficient transportation monitoring which includes papers proposed by Bennett, et al [42] and Shaffiullah, et al [43].

\subsection{Emergency based applications using WSN}

State of emergency can be applicable when any controversial things happen either by environment or by human e.g. criminal activities. People protection both in terms of safety and security terms to be a major concern in such critical situation. WSN are one such solution provider when such critical situations are ahead. WSN networks are well applicable to these scenarios due to its surveillance capability, natural calamity detection and response and disaster emergency response. Przybyla, et al [44] proposed an efficient way to track nuclear based smuggling from its origin to terminus with WSN. Mobile and motionless nodes are used for this surveillance of smuggling. In year 2011, Carpenter, et al [45] proposed a WSN based application to detect nuclear based smuggling materials with the help of radiation detections sensors. When such suspected belonging is identified, GPS and mobile nodes are equipped with alarming capability of that location and mobility. Gray, et al [46] proposed an ontology-based web service for flood forecasting and post flood emergency services with the help of WSN. Li, et al [47] for tracking the flood effects of Poyanghu, China. The proposed technology using WSN provides the environmental changes of water level with the help of field sensor. These data are then collected by base station which further represents the data in graphical format that helps the user to predict the future. Casey, et al [48] proposed an efficient technology for monitoring the underground water pressure monitoring by sensor nodes in WSN. These data are then transferred to base station for predicting Tsunami.

\subsection{Health Care based Applications}

Healthcare applications using WSN plays a vital role in major hospitals by reducing the crowd in such environment. Monitoring patient's health in rural areas facilitates the patients by connecting experts via conferencing and periodic update of patient's health to the doctors. Morreale, et al [49] proposed three different scenarios based WSN for monitoring patient's health care namely Tele-Rehabilitation, Tele-Medicine and Hybrid approach. Tele-Rehabilitation approach consist of sensors for continuous monitoring of patient's status who are affected from bone fracture. These data are then collected 
and diagnosed by Doctor's for further treatment level. Tele-Medicine is the next approach which monitors the odor or room, blankets, etc., are continuously tracked by WSN sensors and updated along with the patient's health conditions for those who are affected by Asthma. Each stage of Asthma can be easily detected with the help of hybrid approach. Ghasemzadeh, et al [50] proposed WSN based human body movement for elder people at home. These nodes in such environment consists of gyroscope and accelerometer apart from microcontroller and radio communicator in conventional sensor nodes of WSN. Ko, et al [51] proposed MEDiSN, which has the potential to monitor heart rate and oxygen level of their blood through deployed sensors in emergency region of waiting room in hospitals. This helps to give preference for the patients who are in need of critical emergency services. Villacorta, et al [52] proposed yet another concept for close monitoring of elder activities in their home. Acoustic type sensors are used for this purpose along with video and RFID. Similar case studies are also handled in this proposed method. Chung, et al [53] proposed TeleHomeCare for efficient assistance for elder people in homes. ZigBee type of communication are used in this proposal with Visual Studio as their front-end interface.

\subsection{Routing Protocols For WSN}

This section describes various kinds of routing protocols proposed in the earlier research works.

\section{Flat Based Routing Protocols}

There are two different categories of routing protocols is in WSN such as network structure based and operation based. Network structure-based routing protocols are again categorized in flat-based routing and hierarchical-based routing and location-based routing. Operation-based routing protocols are again categorized into different categories such as multi-path-based, query-based, QoSbased, Coherent-based and negotiation based. All the nodes are assigned with equal and similar roles in flat-based routing in terms of sensing and data collection. Due to the greatest number of nodes, it is a critical problem in assigning unique ID for all the nodes in the network. Some of the flat-based routing protocols are SPIN [54-55], Directed Diffusion [56], Rumor Routing [57], MCFA [58], GBR [59], IDSQ \& CADR [60], COUGAR [61], ACQUIRE [62], Energy Aware Routing [63] etc.

The performance of the some of the flat-based routing protocols, proposed in earlier research works are given in Table-2 with the description. But each routing protocol has been designed with unique behavior and applications, not for any application under WSN. Hence the performance of the routing protocols needs to be verified to proceed with the proposed methodology of the present research work. Most of the routing protocols are focused to improve the network lifetime with the data transmission.

\section{Table 2. Performance Comparison of Flat-Based Routing Protocols}

\begin{tabular}{|l|l|l|l|l|}
\hline & $\begin{array}{l}\text { SPIN } \\
{[\mathbf{5 5}]}\end{array}$ & $\begin{array}{l}\text { DD } \\
\text { [55] }\end{array}$ & $\begin{array}{l}\text { EAR } \\
{[\mathbf{6 3}]}\end{array}$ & $\begin{array}{l}\text { GBR } \\
\text { [59] }\end{array}$ \\
\hline Classification & $\begin{array}{l}\text { Flat- } \\
\text { based }\end{array}$ & $\begin{array}{l}\text { Flat- } \\
\text { based }\end{array}$ & $\begin{array}{l}\text { Flat- } \\
\text { based }\end{array}$ & $\begin{array}{l}\text { Flat- } \\
\text { based }\end{array}$ \\
\hline $\begin{array}{l}\text { Energy } \\
\text { conservation }\end{array}$ & Good & $\begin{array}{l}\text { Very } \\
\text { Good }\end{array}$ & $\begin{array}{l}\text { Very } \\
\text { Good }\end{array}$ & $\begin{array}{l}\text { Very } \\
\text { Good }\end{array}$ \\
\hline $\begin{array}{l}\text { Network life } \\
\text { time }\end{array}$ & Good & Good & Good & Good \\
\hline Data based & No & Yes & Yes & Yes \\
\hline Multipath & Yes & Yes & Yes & Yes \\
\hline Optimal path & No & No & Yes & Yes \\
\hline Robustness & Yes & Yes & Yes & Yes \\
\hline Scalability & No & No & No & No \\
\hline Security & No & No & Yes & Yes \\
\hline
\end{tabular}

Hierarchical Based Routing Protocols

Hierarchical-based routing is also called as cluster-based routing, in which nodes act in various major roles in the application. In hierarchical structure, nodes having highest energy is used for data gathering and aggregation to save the energy, whereas other nodes are used in the environment to sense and transmit the data. It says that the clusters are a set of sensors deployed in a region as a group and assigned with a leader called as cluster head. Cluster heads are node having highest energy values. Where each cluster nodes should perform their role and transmit their data only to the cluster head. Then cluster head can transmit it to base station. This is the hierarchical manner the entire network performs monitoring and transmitting the dataset. The hierarchical routing comprises of two set of functions one is cluster head election and the other layer is data routing. Some of the existing hierarchical routing protocols are LEACH [64], PEGASIS [65], TEEN [66], APTEEN [67], MECN [68], SMECN [69], SOP [70], Sensor Aggregate routing [71], VGA [72], HPAR [73], TTDD [74] etc. 
Table 3. Performance Comparison Hierarchical Based Routing Protocols

\begin{tabular}{|c|c|c|c|c|c|c|}
\hline & $\begin{array}{l}\text { LEACH } \\
{[37]}\end{array}$ & $\begin{array}{l}\text { PEGASIS } \\
|38|\end{array}$ & $\begin{array}{c}\text { LPEGASIS } \\
|38|\end{array}$ & $\begin{array}{r}\text { TEEN } \\
|39|\end{array}$ & $\begin{array}{l}\text { APTEEN } \\
\text { [40| }\end{array}$ & $\begin{array}{r}\text { TTDD } \\
|47|\end{array}$ \\
\hline Classification & hierarchical & hierarchical & hierarchical & hierarchical & hierarchical & hierarchical \\
\hline Proactive & Yes & Yes & Yes & Yes & Yes & Yes \\
\hline Energy Conservation & Very Good & Very Good & Very Good & Good & Good & Good \\
\hline Network Life Time & Good & Very Good & Very Good & Very Good & better & Good \\
\hline Data-Based & $\mathrm{N}_{0}$ & Yes & Yes & Yes & Yes & Yes \\
\hline Data Aggregation & Yes & Yes & Yes & Yes & Yes & No \\
\hline Location-Based & $\mathrm{N}_{0}$ & No & No & No & No & Yes \\
\hline (Qos-Supported & $\mathrm{N}_{0}$ & No & No & No & No & Yes \\
\hline Multipath & $\mathrm{N}_{0}$ & No & No & No & No & No \\
\hline Optimal Path & No & No & No & No & No & No \\
\hline Robustness & better & better & better & better & better & Good \\
\hline Scalability & Good & Good & Good & Good & Good & common \\
\hline Security & $\mathrm{N}_{0}$ & $\mathrm{~N}_{0}$ & $\mathrm{~N}_{0}$ & No & No & No \\
\hline
\end{tabular}

In this section, the performance of the some of the routing protocols, proposed in earlier research works are given in Table-3 with the description. But each routing protocol has been designed with unique behavior and applications, not for any application under WSN. Hence the performance of the routing protocols needs to be verified to proceed with the proposed methodology of the present research work. Most of the routing protocols are focused to improve the network lifetime with the data transmission.

Table 4. Performance Comparison of Flat-Based Routing Protocols

\begin{tabular}{|l|l|l|l|l|}
\hline & $\begin{array}{l}\text { GAF } \\
{[\mathbf{5 2}]}\end{array}$ & $\begin{array}{l}\text { GPSR } \\
{[\mathbf{5 4 ]}}\end{array}$ & $\begin{array}{l}\text { DIR } \\
{[\mathbf{5 5}]}\end{array}$ & $\begin{array}{l}\text { SPAN } \\
{[\mathbf{5 7 ]}}\end{array}$ \\
\hline $\begin{array}{l}\text { Classificati } \\
\text { on }\end{array}$ & $\begin{array}{l}\text { Locatio } \\
\text { n-Based }\end{array}$ & $\begin{array}{l}\text { Locatio } \\
\text { n-Based }\end{array}$ & $\begin{array}{l}\text { Locatio } \\
\text { n-Based }\end{array}$ & $\begin{array}{l}\text { Locatio } \\
\text { n-Based }\end{array}$ \\
\hline $\begin{array}{l}\text { Energy } \\
\text { conservatio } \\
\text { n }\end{array}$ & $\begin{array}{l}\text { Very } \\
\text { Good }\end{array}$ & $\begin{array}{l}\text { Very } \\
\text { Good }\end{array}$ & $\begin{array}{l}\text { Very } \\
\text { Good }\end{array}$ & $\begin{array}{l}\text { Very } \\
\text { Good }\end{array}$ \\
\hline $\begin{array}{l}\text { Network } \\
\text { life time }\end{array}$ & $\begin{array}{l}\text { Very } \\
\text { Good }\end{array}$ & Good & Good & $\begin{array}{l}\text { Very } \\
\text { Good }\end{array}$ \\
\hline Data based & Yes & Yes & Yes & Yes \\
\hline Multipath & Yes & Yes & Yes & Yes \\
\hline $\begin{array}{l}\text { Optimal } \\
\text { path }\end{array}$ & No & No & Yes & Yes \\
\hline Robustness & Yes & Yes & Yes & Yes \\
\hline Scalability & No & No & No & Yes \\
\hline Security & No & No & Yes & Yes \\
\hline
\end{tabular}

\section{Location Based Routing Protocols}

Sensor nodes are deployed by knowing their location in location-based routing. It helps to obtain shortest path, and node location to avoid sink or sybil attack in the network. Also, the closest true neighbor can be calculated according to the node's location. Distance among the nodes can be estimated by the signal strength. Coordinates of the nodes can be obtaining by verifying their true locations for transmitting their information and data among the neighbors [75-77]. Another way to obtain the node location is by communicating with the nodes using GPS and satellite. It is possible only with the sensor nodes inbuilt with a low power GPS receiver [78]. Some of the locationbased routing protocols are GAF [79], GEAR [80], GPSR [81], MFR, DIR, GEDIR [82], GOAFR [83], SPAN [84] etc.

\section{Optimization Strategies in WSN}

Optimization comes into picture when using exact methods become an inefficient approach or infeasible to find best results. This infeasible nature arises when the solution space becomes large or infinite. At the earlier stage of optimization, mathematical optimization techniques played a vital role for solving NP-Hard problems. During this session, Newton's method, Quassi-Newton's method, Conjugate gradient method, Ellipsoid method, Powell's method, Nelder -Mead, Cauchy method, Newton Rapson method, etc., are the non-deterministic approaches for solving such problems. Next to mathematical optimization techniques there comes heuristic approaches for solving the problems with less computational cost. Heuristic approach is problem dependent. These approaches are derived for solving a particular problem in efficient manner. Some of the heuristic approaches includes Tabu Search, Turn restriction Routing [85], etc. In the year 1970, John Holland introduced Genetic Algorithm (GA) which is based on Evolutionary strategy of reproduction mechanism. This approach is the first evolutionary algorithm which is iterative and stochastic in nature. After the evolution of Genetic Algorithm, swarm-based algorithm evolved in early 1990. Swarm based algorithms works together to find optimal results in large solution space and they are named as swarm intelligence. Some of the approaches of swarm intelligence algorithms are Ant Colony Optimization (ACO), Particle swarm Optimization (PSO), etc. Evolutionary computing is well suitable for solving problems in WSN since the number of feasible solutions in the solution space of WSN problems are infinite. Applications of evolutionary algorithms in WSN include data aggregation, energy efficiency, Node Deployment, Node Localization, Node Clustering, etc.

The basic mechanism for finding optimal results by evolutionary algorithms includes five stages. They are Initialization, Solution Representation, Fitness Calculation, Evolution Strategy and Selection Mechanism. 


\section{Initialization}

Initialization is the process of defining the variables that are appropriate for the algorithm to solve given problem. Initialization also includes population generation where the feasible random solutions are prepared. During the initialization process the objective function, decision variable space should be defined.

\section{Solution Representation}

Solution representation is the way to represent your solution space which can be handled by the algorithm for finding optimal solution from it. Solution representation are in different types which includes Binary representation, Discrete, Continuous, tree structured, etc. this representation of solution will be carried out throughout the process with the help of boundary check or solution repairing methods.

\section{Fitness Calculation}

Fitness calculation is a problem dependent function which is used to evaluate the solution with respect to the objective defined. This fitness value for each solution are evaluated for the purpose of finding which solution is nearer to the given objective. If more than one objective is defined, then multi-objective optimization procedure will be used which includes external archive for finding Pareto optimal solutions for each objective.

\section{Solving WSN problems with EA gives prominent results when compared to other time-consuming algorithms.}

Table 5 presents the problems of WSN which are efficiently handled by EA. The Table consists of six attributes which are as follows: Author Name, Algorithm used to solve the respective problem of WSN, Subdomain of WSN in which the algorithm produced the results, Solution Representation, Number of Objectives solved with the algorithm and other contributions of the paper.

Table 5. State of Art on Evolutionary Algorithms in the domain of Wireless Sensor Network

\begin{tabular}{|c|c|c|c|c|}
\hline Author & $\begin{array}{c}\text { Algorithm } \\
\text { Used }\end{array}$ & $\begin{array}{c}\text { Area of } \\
\text { Optimization } \\
\end{array}$ & $\begin{array}{l}\text { Objective } \\
\text { Space }\end{array}$ & Contribution \\
\hline $\begin{array}{l}\text { Abo-Zahhad, } \\
\text { et al [86] }\end{array}$ & $\begin{array}{l}\text { Immune- } \\
\text { Voronoi } \\
\text { Algorithm } \\
\end{array}$ & $\begin{array}{l}\text { Node } \\
\text { Deployment }\end{array}$ & Bi-Objective & $\begin{array}{l}\text { 1. Enhances the coverage region of nodes } \\
\text { 2. Increases the lifetime of network }\end{array}$ \\
\hline $\begin{array}{l}\text { Bhatia, et al } \\
\text { [87] }\end{array}$ & $\begin{array}{l}\text { Genetic } \\
\text { Algorithm }\end{array}$ & $\begin{array}{l}\text { Distant Aware } \\
\text { Routing }\end{array}$ & $\begin{array}{l}\text { Single- } \\
\text { Objective }\end{array}$ & $\begin{array}{l}\text { 1. Genetic Algorithm is used for cluster head } \\
\text { selection } \\
\text { 2.Multiple Criteria are used to achieve } \\
\text { practical simulation in fitness calculation. }\end{array}$ \\
\hline $\begin{array}{l}\text { Gupta, et al } \\
{[88]}\end{array}$ & $\begin{array}{l}\text { Genetic } \\
\text { Algorithm }\end{array}$ & $\begin{array}{l}\text { Node } \\
\text { Deployment }\end{array}$ & $\begin{array}{l}\text { Multi- } \\
\text { Objective }\end{array}$ & $\begin{array}{l}\text { 1.GA is used for finding efficient positions } \\
\text { to place sensor nodes to cover all regions } \\
\text { and receive all data from other nodes. } \\
2 . \text { The three objectives are minimizing } \\
\text { number of sensor nodes used, maximize the } \\
\text { coverage region and maximize the } \\
\text { connectivity }\end{array}$ \\
\hline
\end{tabular}

Evolution strategy is the process of altering the solutions of current iteration in order to move closer to the objectives in next iteration. This strategy differs from algorithm to algorithm. E.g. in PSO the velocity and position of solutions are updated, in ACO pheromone table is updated based on the probability next generation solutions are produced, in GA reproduction mechanism is used

\section{Selection Mechanism}

Selection mechanism is defined as the method that decides which solutions can be chosen to participate in the next eneration of algorithm. This method is optional in

\section{WSN problems solution set using Evolutionary algorithms} provisional. Due to that the solution models for those
problems are not static. Since the network is ad-hoc type, provisional. Due to that the solution models for those
problems are not static. Since the network is ad-hoc type, using static solutions set becomes infeasible die to
environmental changes. Designing an algorithm for esigning an algorithm for adapting dynamic changes in the network becomes a adapting dynamic changes in the network becomes a
tedious task. On the other hand, EA outperforms over other
algorithms for producing fast and efficient solution sets within given time. Emergence of EA are much superior when compared to its growth in the early stages.

\section{Evolution Strategy}

Wireless Sensor Network problems are highly dynamic and within

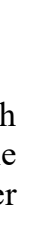




\begin{tabular}{|c|c|c|c|c|}
\hline $\begin{array}{l}\text { Shankar, T. et } \\
\text { al [89] }\end{array}$ & $\begin{array}{l}\text { Hybrid PSO and } \\
\text { Harmony } \\
\text { Search }\end{array}$ & $\begin{array}{c}\text { Data } \\
\text { Aggregation }\end{array}$ & $\begin{array}{l}\text { Single } \\
\text { Objective }\end{array}$ & $\begin{array}{l}\text { 1. PSO is used for Exploration and HS is } \\
\text { used for exploitation in choosing cluster } \\
\text { head }(\mathrm{CH}) \text {. } \\
\text { 2. Results are better than PSO in terms of } \\
\text { throughput and residual energy of } \mathrm{CH} \text {. }\end{array}$ \\
\hline $\begin{array}{l}\text { Ozdag, et al } \\
\quad[90]\end{array}$ & $\begin{array}{l}\text { Electromagnetis } \\
\text { m like } \\
\text { Algorithm(EM) }\end{array}$ & $\begin{array}{l}\text { Node } \\
\text { Distribution }\end{array}$ & $\begin{array}{l}\text { Single } \\
\text { Objective }\end{array}$ & $\begin{array}{l}\text { 1. EM to increase the coverage region by } \\
\text { distributing the nodes randomly. }\end{array}$ \\
\hline $\begin{array}{l}\text { Zahedi, et al } \\
\qquad[91]\end{array}$ & $\begin{array}{l}\text { Firefly } \\
\text { Algorithm }\end{array}$ & Routing & $\begin{array}{l}\text { Single } \\
\text { Objective }\end{array}$ & $\begin{array}{l}\text { 1. Firefly algorithm is to optimize the fuzzy } \\
\text { table which is used to distribute the nodes } \\
\text { to clusters uniformly. } \\
\text { 2. With swarm based fuzzy logic balanced } \\
\text { clusters are produced and results are } \\
\text { tabulated. }\end{array}$ \\
\hline $\begin{array}{l}\text { Shokouhifar, } \\
\text { et al [92] }\end{array}$ & $\begin{array}{l}\text { Genetic } \\
\text { Algorithm }\end{array}$ & Routing & $\begin{array}{l}\text { Single } \\
\text { Objective }\end{array}$ & $\begin{array}{l}\text { 1. GA is used for cluster head selection by } \\
\text { considering } 3 \text { constraints. } \\
\text { 2. Proposed system achieves significant } \\
\text { prolonged network lifetime. }\end{array}$ \\
\hline $\begin{array}{l}\text { Khalesian, et al } \\
\text { [93] }\end{array}$ & $\begin{array}{l}\text { Genetic } \\
\text { Algorithm }\end{array}$ & $\begin{array}{l}\text { Node } \\
\text { Deployment }\end{array}$ & $\begin{array}{l}\text { Multi } \\
\text { Objective }\end{array}$ & $\begin{array}{l}\text { 1. Genetic algorithm operators are used to } \\
\text { converge the feasible solutions to produce } \\
\text { optimal solutions. } \\
\text { 2. Multi-objective approach is used to find } \\
\text { pareto optimal solutions }\end{array}$ \\
\hline $\begin{array}{l}\text { Vipin Pal, et al } \\
{[94]}\end{array}$ & $\begin{array}{l}\text { Genetic } \\
\text { Algorithm }\end{array}$ & $\begin{array}{l}\text { Load } \\
\text { Balancing }\end{array}$ & $\begin{array}{l}\text { Single } \\
\text { Objective }\end{array}$ & $\begin{array}{l}\text { 1. GA is used for cluster head selection to } \\
\text { balance the network. } \\
2 . \text { With the interpretation of simulated } \\
\text { results, it is identified that the lifetime of } \\
\text { network is prolonged }\end{array}$ \\
\hline $\begin{array}{l}\text { Sun Xeumei, } \\
\text { et al }[95]\end{array}$ & $\begin{array}{c}\text { Hybrid Ant } \\
\text { Colony and } \\
\text { Culture } \\
\text { Algorithm (CA- } \\
\text { ACA) }\end{array}$ & $\begin{array}{c}\text { Node } \\
\text { Deployment }\end{array}$ & $\begin{array}{c}\text { Single } \\
\text { Objective }\end{array}$ & $\begin{array}{l}\text { 1. Use of culture algorithm improves the } \\
\text { stability in Ant colony algorithm for finding } \\
\text { optimal solutions. } \\
\text { 2. Convergence Judging Method is used to } \\
\text { avoid premature convergence }\end{array}$ \\
\hline $\begin{array}{l}\text { Potthuri, et al } \\
{[96]}\end{array}$ & $\begin{array}{l}\text { Hybrid } \\
\text { Differential } \\
\text { Evolution and } \\
\text { Simulated } \\
\text { Annealing }\end{array}$ & $\begin{array}{l}\text { Cluster Head } \\
\text { Selection }\end{array}$ & $\begin{array}{c}\text { Single } \\
\text { Objective }\end{array}$ & $\begin{array}{l}\text { 1. Improves the network lifetime by } \\
\text { switching the cluster heads dynamically } \\
\text { and efficiently. } \\
\text { 2. Results shows a decline in number of } \\
\text { dead nodes when compared to other } \\
\text { algorithms }\end{array}$ \\
\hline $\begin{array}{c}\text { Taherian, et al } \\
{[97]}\end{array}$ & $\begin{array}{l}\text { Particle Swarm } \\
\text { Optimization }\end{array}$ & Routing & $\begin{array}{c}\text { Single } \\
\text { Objective }\end{array}$ & $\begin{array}{l}\text { 1. Clustering of nodes are done by } \\
\text { unsupervised learning technique and } \\
\text { routing between nodes are achieved by } \\
\text { PSO. }\end{array}$ \\
\hline $\begin{array}{l}\text { Kuila, et al } \\
\text { [98] }\end{array}$ & $\begin{array}{c}\text { Differential } \\
\text { Evolution (DE) }\end{array}$ & $\begin{array}{l}\text { Cluster Head } \\
\text { Selection }\end{array}$ & $\begin{array}{c}\text { Single } \\
\text { Objective }\end{array}$ & $\begin{array}{l}\text { 1. Dynamically allocates } \mathrm{CH} \text { based on } \\
\text { residual energy to reduce the node death } \\
\text { using DE. } \\
\text { 2. A local improvement method is used to } \\
\text { avoid premature convergence. }\end{array}$ \\
\hline $\begin{array}{c}\text { Kuila, et al } \\
\text { [99] }\end{array}$ & $\begin{array}{l}\text { Particle Swarm } \\
\text { Optimization }\end{array}$ & Routing & $\begin{array}{l}\text { Multi- } \\
\text { Objective }\end{array}$ & $\begin{array}{l}\text { 1. PSO is used to determine routing schema } \\
\text { for efficient data transfer. } \\
\text { 2. Clustering algorithm is also used for } \\
\text { efficient load balancing. }\end{array}$ \\
\hline Lu, et al [100] & $\begin{array}{l}\text { Ant Colony } \\
\text { Optimization }\end{array}$ & $\begin{array}{c}\text { Node } \\
\text { Deployment }\end{array}$ & $\begin{array}{c}\text { Multi } \\
\text { Objective }\end{array}$ & $\begin{array}{l}\text { 1. ACO is used to allocate the node to } \\
\text { achieve maximum coverage of network } \\
\text { using probability distribution. } \\
\text { 2. Greedy migration technique is } \\
\text { incorporated for fast convergence towards } \\
\text { global solution. }\end{array}$ \\
\hline
\end{tabular}




\begin{tabular}{|c|c|c|c|c|}
\hline $\mathrm{Lu}$, et al [101] & $\begin{array}{l}\text { Particle Swarm } \\
\text { Optimization }\end{array}$ & $\begin{array}{c}\text { Data } \\
\text { Aggregation }\end{array}$ & $\begin{array}{c}\text { Multi } \\
\text { Objective }\end{array}$ & $\begin{array}{l}\text { 1. Heuristic algorithm is imposed with PSO } \\
\text { for efficient data aggregation. } \\
\text { 2. Double layer encoding is used for finding } \\
\text { pareto optimal solutions using PSO. }\end{array}$ \\
\hline $\begin{array}{l}\text { Gajjar, et al } \\
\text { [102] }\end{array}$ & $\begin{array}{l}\text { Ant Colony } \\
\text { Optimization }\end{array}$ & $\begin{array}{l}\text { Routing and } \\
\text { Cluster Head } \\
\text { Selection }\end{array}$ & $\begin{array}{l}\text { Single } \\
\text { Objective }\end{array}$ & $\begin{array}{l}\text { 1. Multiple constraints are considered for } \\
\text { efficient multi hop routing. } \\
\text { 2. Cluster mechanism based on inequality is } \\
\text { used for efficient data constraints. }\end{array}$ \\
\hline $\begin{array}{l}\text { Zhang, et al } \\
\quad[103]\end{array}$ & $\begin{array}{l}\text { Genetic } \\
\text { Algorithm }\end{array}$ & $\begin{array}{l}\text { Scheduling for } \\
\text { Set cover } \\
\text { problem }\end{array}$ & $\begin{array}{c}\text { Single } \\
\text { objective }\end{array}$ & $\begin{array}{l}\text { 1. GA is used to schedule the sensors for } \\
\text { better energy conservation } \\
\text { 2. Another approach as redundant trend } \\
\text { scheduling of sensor nodes are incorporated } \\
\text { in this paper. }\end{array}$ \\
\hline $\begin{array}{l}\text { Ye, Miao, et al } \\
{[104]}\end{array}$ & $\begin{array}{l}\text { Genetic } \\
\text { Algorithm }\end{array}$ & $\begin{array}{c}\text { Minimum } \\
\text { Exposure Path }\end{array}$ & $\begin{array}{l}\text { Multi- } \\
\text { objective }\end{array}$ & $\begin{array}{l}\text { 1. efficient crossover operator is used for } \\
\text { exploitation purpose. } \\
\text { 2. to avoid premature convergence upside } \\
\text { down operator is introduced. }\end{array}$ \\
\hline $\begin{array}{l}\text { Guo, et al } \\
{[105]}\end{array}$ & $\begin{array}{l}\text { Particle Swarm } \\
\text { Optimization }\end{array}$ & $\begin{array}{l}\text { Task } \\
\text { Allocation } \\
\text { Problem }\end{array}$ & $\begin{array}{l}\text { Single } \\
\text { Objective }\end{array}$ & $\begin{array}{l}\text { 1. Discrete PSO is proposed for adapting } \\
\text { the scheduling problem to PSO. } \\
\text { 2. Proposed model improves the utilization } \\
\text { of resources, allocation of tasks, etc. }\end{array}$ \\
\hline $\begin{array}{l}\text { Regina Pravin, } \\
\text { et al [106] }\end{array}$ & $\begin{array}{l}\text { Particle Swarm } \\
\text { Optimization }\end{array}$ & Cluster & $\begin{array}{l}\text { Single } \\
\text { Objective }\end{array}$ & $\begin{array}{l}\text { 1. A cluster assistant node methodology is } \\
\text { introduced to reduce the overhead of CH. } \\
2 \text {. PSO runs until all the nodes in the } \\
\text { network becomes a member of a cluster. }\end{array}$ \\
\hline $\begin{array}{l}\text { Murugeswari, } \\
\text { et al. [107] }\end{array}$ & NSGA II & Routing & Bi-objective & $\begin{array}{l}\text { 1. Dynamic crowding distance method is } \\
\text { incorporated in NSGA II for efficient } \\
\text { routing. } \\
\text { 2. Transmission count and transmission } \\
\text { delay are the two objectives chosen }\end{array}$ \\
\hline $\begin{array}{l}\text { Lanza, et al } \\
\quad[108]\end{array}$ & $\begin{array}{l}\text { Multi-objective } \\
\text { Evolutionary } \\
\text { Algorithms } \\
\end{array}$ & $\begin{array}{c}\text { Node } \\
\text { Deployment }\end{array}$ & $\begin{array}{c}\text { Multi } \\
\text { objective }\end{array}$ & $\begin{array}{l}\text { 1. MO-ABC, NSGA II, SPEA 2, MOEA/D, } \\
\text { Mo-FF are the algorithms used to solve } \\
\text { relay node deployment in this paper }\end{array}$ \\
\hline $\begin{array}{l}\text { Wang, et al } \\
\quad[109]\end{array}$ & $\begin{array}{l}\text { Ant Colony } \\
\text { Optimization }\end{array}$ & $\begin{array}{l}\text { QoS based } \\
\text { Routing }\end{array}$ & Bi-objective & $\begin{array}{l}\text { 1. QoS in terms of consumption of energy } \\
\text { and performance of network are considered } \\
\text { for finding efficient route to reach from } \\
\text { source to destination. } \\
\text { 2. Packet delivery ration and energy } \\
\text { consumption are achieved better using } \\
\text { proposed algorithm. }\end{array}$ \\
\hline $\begin{array}{l}\text { Qiao, et al } \\
\quad[110]\end{array}$ & $\begin{array}{l}\text { Multi objective } \\
\text { evolution } \\
\text { algorithm }\end{array}$ & $\begin{array}{c}\text { Node } \\
\text { Localization }\end{array}$ & Bi- objective & $\begin{array}{l}\text { 1. PAES is used to handle the optimization } \\
\text { of node localization and MOEA is used to } \\
\text { handle the initial decision vector. }\end{array}$ \\
\hline $\begin{array}{l}\text { Prakit } \\
\text { Goswami, et } \\
\text { al [111] }\end{array}$ & $\begin{array}{l}\text { Firefly } \\
\text { Algorithm }\end{array}$ & Clustering & $\begin{array}{c}\text { Single } \\
\text { Objective }\end{array}$ & $\begin{array}{l}\text { Firefly algorithm is used to choose the } \\
\text { nodes whether to act as a cluster member of } \\
\text { a particular cluster or not using binary } \\
\text { value. }\end{array}$ \\
\hline$\frac{\text { ZiweiYan, et }}{\text { al [112] }}$ & $\begin{array}{c}\text { Particle Swarm } \\
\text { Optimization }\end{array}$ & $\begin{array}{c}\text { Node } \\
\text { Positioning } \\
\end{array}$ & $\begin{array}{l}\text { Single } \\
\text { Objective }\end{array}$ & $\begin{array}{l}\text { To optimize the position of nodes to reduce } \\
\text { the overall energy consumption }\end{array}$ \\
\hline$\frac{\underline{\text { Karishma }}}{\underline{\text { Singh, et al. }}}$ & PSOGSA & $\begin{array}{l}\text { Node } \\
\text { Positioning }\end{array}$ & $\begin{array}{l}\text { Multi- } \\
\text { objective }\end{array}$ & $\begin{array}{l}\text { To regulate the arrival rate of data based on } \\
\text { the priority of the data packet and also } \\
\text { minimized energy consumption of node }\end{array}$ \\
\hline $\begin{array}{l}\text { Ziwen Sun, et } \\
\text { al. [114] }\end{array}$ & $\begin{array}{l}\text { Ant Colony } \\
\text { Optimization }\end{array}$ & Routing & $\begin{array}{l}\text { Multi- } \\
\text { objective }\end{array}$ & $\begin{array}{l}\text { Based on the trust values of each node the } \\
\text { routing has been built for secure transfer of } \\
\text { messages }\end{array}$ \\
\hline
\end{tabular}


From the Table 5, the areas in which EA can contribute its influence can be easily derived. With this knowledge, further proceedings can be made by the researchers. And the solution representation which is the most predominant feature needed to map EA with WSN problem is stated clearly. This can assist the researcher to carry on with the other parts of algorithm.

\section{Conclusion}

The main objective of this paper is to provide a survey on various methods and routing protocols have been used to improve the energy efficiency. Recent real-time applications are designed in WSN. In order to improve the QoS of application of WSN, it is essential to provide a better methodology or approach for increasing the energy efficiency. Hence this paper aimed to discuss about Evolutionary Algorithms and various routing protocols focused on enhancing the energy efficiency in WSN. We have done a comprehensive survey on the application of WSN and solving methodologies of WSN problems using Evolutionary algorithms. This given survey describes the applications of WSN in different scenarios. With that intended survey then the paper focused towards Evolutionary algorithms and its need in WSN. A brief introduction on mechanism of Evolutionary algorithm has been described and an overall layout of the process tangled in evolutionary algorithms for optimizing a problem has been given. Table 1 shows a detailed and precise knowledge of EA impact in WSN domain has been listed. It also discussed about different kinds of routing protocols and the performance comparison. Based on the performance comparison given in Table-2, 3 and 4, it is identified that the routing protocols have obtained better energy in WSN applications. The survey comprises of the papers published in the past two years since many other survey articles specified the previous papers which are published and the details of other survey are given here. This paper is an attempt to provide a clear-cut knowledge of EA on WSN problems. In future this paper can be expanded to contain evolutionary algorithm specified problem solving methods along with its variants.

In future work, based on this survey, a novel energy efficient methodology or routing protocol will be designed for any application in WSN.

\section{References}

[1] Ali, A., Ming, Y., Chakraborty, S., \& Iram, S. (2017). A comprehensive survey on real-time applications of WSN. Future internet, 9(4), 77.

[2] Matin, M. A., \& Islam, M. M. (2012). Overview of wireless sensor network. Wireless Sensor Networks-Technology and Protocols, 1-3.

[3] Ajami, S., \& Khaleghi, L. (2015). A review on equipped hospital beds with wireless sensor networks for reducing bedsores. Journal of research in medical sciences: the official journal of Isfahan University of Medical Sciences, 20(10), 1007.
[4] Darwish, A., \& Hassanien, A. E. (2011). Wearable and implantable wireless sensor network solutions for healthcare monitoring. Sensors, 11(6), 5561-5595.

[5] Rajeswari, P., Pratheeba, S., \& Karthika, S. R. (2014). A Comprehensive Overview on Different Applications of Wireless Sensor Network. International Journal of Engineering and Advanced Technology (IJEAT), 3(4), 8084.

[6] S.R.Jino Ramson D.Jackuline Moni, (2018), "Applications of Wireless Sensor Networks - A Survey", IEEE International Conference, DOI: 10.1109/ICIEEIMT.2017.8116858.

[7] Matin, M. A., \& Islam, M. M. (2012). Overview of wireless sensor network. Wireless Sensor Networks-Technology and Protocols, 1-3.

[8] Carlos-Mancilla, M., López-Mellado, E., \& Siller, M. (2016). Wireless sensor networks formation: approaches and techniques. Journal of Sensors, 2016.

[9] S.R.Jino Ramson D.Jackuline Moni, (2018), "Applications of Wireless Sensor Networks - A Survey", IEEE International Conference, DOI: 10.1109/ICIEEIMT.2017.8116858.

[10] Carlos-Mancilla, M., López-Mellado, E., \& Siller, M. (2016). Wireless sensor networks formation: approaches and techniques. Journal of Sensors, 2016.

[11] Ketshabetswe, L. K., Zungeru, A. M., Mangwala, M., Chuma, J. M., \& Sigweni, B. (2019). Communication protocols for wireless sensor networks: A survey and comparison. Heliyon, 5(5), e01591.

[12] Sen, J. (2012). Security in wireless sensor networks. Wireless Sensor Networks: Current Status and Future Trends, 407, 408.

[13] Akkaş, M. A., \& Sokullu, R. (2015). Wireless underground sensor networks: channel modeling and operation analysis in the terahertz band. International Journal of Antennas and Propagation, 2015.

[14] Xu, G., Shen, W., \& Wang, X. (2014). Applications of wireless sensor networks in marine environment monitoring: A survey. Sensors, 14(9), 16932-16954.

[15] Zhou, Z., Yao, B., Xing, R., Shu, L., \& Bu, S. (2015). ECARP: An energy efficient routing protocol for UWSNs in the internet of underwater things. IEEE Sensors Journal, 16(11), 4072-4082.

[16] Adu-Manu, K. S., Tapparello, C., Heinzelman, W., Katsriku, F. A., \& Abdulai, J. D. (2017). Water quality monitoring using wireless sensor networks: Current trends and future research directions. ACM Transactions on Sensor Networks (TOSN), 13(1), 1-41.

[17] Engmann, F., Katsriku, F. A., Abdulai, J. D., Adu-Manu, K. S., \& Banaseka, F. K. (2018). Prolonging the lifetime of wireless sensor networks: a review of current techniques. Wireless Communications and Mobile Computing, 2018.

[18] Akande, D. O., \& Salleh, M. F. M. (2019). A network lifetime extension-aware cooperative MAC protocol for MANETs with optimized power control. IEEE Access, 7, 18546-18557.

[19] Torrado, J. M. (2018). Modeling and Analysis of Energy Harvesting IoT Networks (Master's thesis)

[20] Meena, S. S., \& Manikandan, J. (2017, March). Study and evaluation of different topologies in wireless sensor network. In 2017 International Conference on Wireless Communications, Signal Processing and Networking (WiSPNET) (pp. 107-111). IEEE

[21] Desai, U. B., Jain, B. N., \& Merchant, S. N. (2007, April). Wireless sensor networks: technology roadmap. 
In Workshop on Wireless Sensor Networks at IITB on April (Vol. 20, p. 2007).

[22] Al-Karaki, J. N., \& Kamal, A. E. (2004). Routing techniques in wireless sensor networks: a survey. IEEE wireless communications, 11(6), 6-28.

[23] Xiao, G., Wang, R., Zhang, C., \& Ni, A. (2020). Demand prediction for a public bike sharing program based on spatio-temporal graph convolutional networks. Multimedia Tools and Applications, 1-19.

[24] Akyildiz, Ian F., et al. "Wireless sensor networks: a survey." Computer networks 38.4 (2002): 393-422.

[25] Yick, Jennifer, Biswanath Mukherjee, and Dipak Ghosal. "Wireless sensor network survey." Computer networks 52.12 (2008): 2292-2330.

[26] Adnan, Md Akhtaruzzaman, et al. "Bio-mimic optimization strategies in wireless sensor networks: A survey." Sensors 14.1 (2013): 299-345.

[27] Lim Y, Kim H-M, Kang S. A design of wireless sensor networks for a power quality monitoring system. IEEE Sens 2010;10: 9712-25.

[28] Cao L, Jiang W, Zhang Z. Networked wireless meter reading system based on zigbee technology. In: Control and decision conference; 2008

[29] Lin Z-T, Zheng J, Ji Y-S, Zhao B-H, Qu Y-G, Huang X-D, et al. EMMNET: sensor networking for electricity meter monitoring. IEEE Sens 2010;10: 6307-23.

[30] Ahmad J, Malik AS, Abdullah MF, Kamel N, Xia L. A novel method for vegetation encroachment monitoring of transmission lines using a single $2 \mathrm{~d}$ camera. Pattern Anal Appl 2015; 18: 419-40.

[31] Yang Y, Lambert F, Divan D. A survey on technologies for implementing sensor networks for power delivery systems. In: IEEE power engineering society general meeting; 2007

[32] Nadeem T, Dashtinezhad S, Liao C, Iftode L. Trafficview: a scalable traffic monitoring system. In: 2004 Proceedings of IEEE international conference on mobile data management; 2004

[33] Nadeem T, Dashtinezhad S, Liao C, Iftode L. Trafficview: a scalable traffic monitoring system. In: 2004 Proceedings of IEEE international conference on mobile data management; 2004.

[34] Curiac D-I, Volosencu C. Urban traffic control system architecture based on wireless sensor-actuator networks. In: Proceedings of the 2nd international conference on manufacturing engineering, quality and production systems; 2010.

[35] Ferreira M, Fernandes R, Conceição H, Viriyasitavat W, Tonguz OK. Self-organized traffic control. In: Proceedings of the seventh ACM international workshop on VehiculAr InterNETworking; 2010.

[36] Bruno R, Conti M, Gregori E. Mesh networks: commodity multihop ad hoc net- works. IEEE Commun Mag 2015; 43:123-31.

[37] Rahim A, Khan ZS, Muhaya FT, Sher M, Kim T-H. Sensor based framework for secure multimedia communication in vanet. IEEE Sens 2010; 10:10146-54.

[38] Yoo, Seong-eun. "A wireless sensor network-Based portable vehicle detector evaluation system." Sensors 13.1 (2013): 1160-1182.

[39] Ceriotti, Matteo, et al. "Is there light at the ends of the tunnel? Wireless sensor networks for adaptive lighting in road tunnels." Information Processing in Sensor Networks (IPSN), 2011 10th International Conference on. IEEE, 2011.

[40] Tang, Vanessa WS, Yuan Zheng, and Jiannong Cao. "An intelligent car park management system based on wireless sensor networks." Pervasive Computing and Applications, 2006 1st International Symposium on. IEEE, 2006.

[41] Stajano, F., Hoult, N., Wassell, I., Bennett, P., Middleton, C., \& Soga, K. (2010). Smart bridges, smart tunnels: Transforming wireless sensor networks from research prototypes into robust engineering infrastructure. Ad Hoc Networks, 8(8), 872-888.

[42] Bennett, Peter J., et al. "Wireless sensor networks for underground railway applications: case studies in Prague and London." Smart Structures and Systems 6.5-6 (2010): 619-639.

[43] Shafiullah, G. M., Amoakoh Gyasi-Agyei, and Peter Wolfs. "Survey of wireless communications applications in the railway industry." Wireless Broadband and Ultra Wideband Communications, 2007. AusWireless 2007. The 2nd International Conference on. IEEE, 2007.

[44] Przybyla, Jay, Jeffrey Taylor, and Xuesong Zhou. "Locating Sensors for Detecting Source-to-Target Patterns of Special Nuclear Material Smuggling: A Spatial Information Theoretic Approach." Sensors 10.9 (2010): 8070-8091.

[45] Carpenter, Tamra, et al. "Sensor management problems of nuclear detection." Safety and Risk Modeling and Its Applications. Springer London, 2011. 299-323.

[46] Gray, A. J., Sadler, J., Kit, O., Kyzirakos, K., Karpathiotakis, M., Calbimonte, J. P., ... \& Fernandes, A. A. (2011). A semantic sensor web for environmental decision support applications. Sensors, 11(9), 8855-8887.

[47] Li, X., Cheng, X., Gong, P., \& Yan, K. (2011). Design and implementation of a wireless sensor network-based remote water-level monitoring system. Sensors, 11(2), 1706-1720.

[48] Casey, Kenan, Alvin Lim, and Gerry Dozier. "A sensor network architecture for tsunami detection and response." International Journal of Distributed Sensor Networks 4.1 (2008): 27-42.

[49] Morreale, Patricia A. "Wireless sensor network applications in urban telehealth." Advanced Information Networking and Applications Workshops, 2007, AINAW'07. 21st International Conference on. Vol. 2. IEEE, 2007.

[50] Ghasemzadeh, H., Barnes, J., Guenterberg, E., \& Jafari, R. (2008, September). A phonological expression for physical movement monitoring in body sensor networks. In Mobile Ad Hoc and Sensor Systems, 2008. MASS 2008. 5th IEEE International Conference on (pp. 58-68). IEEE.

[51] Ko, JeongGil, Tia Gao, and Andreas Terzis. "Empirical study of a medical sensor application in an urban emergency department." Proceedings of the Fourth International Conference on Body Area Networks. ICST (Institute for Computer Sciences, Social-Informatics and Telecommunications Engineering), 2009.

[52] Villacorta, J. J., Jiménez, M. I., Val, L. D., \& Izquierdo, A. (2011). A configurable sensor network applied to ambient assisted living. Sensors, 11(11), 10724-10737.

[53] Chung, Yu-Fang, and Chia-Hui Liu. "Design of a wireless sensor network platform for tele-homecare." Sensors 13.12 (2013): 17156-17175.

[54] Mulligan, R., Ammari, M.H., 2010. Coverage in wireless sensor networks: a survey. Network Protocols Algorithms 2 (2), 27-53.

[55] W. Heinzelman, J. Kulik, and H. Balakrishnan, "Adaptive Protocols for Information Dissemination in Wireless Sensor Networks," Proc. 5th ACM/IEEE Mobicom Conference (MobiCom '99), Seattle, WA, August, 1999. pp. 174-85.

[56] J. Kulik, W. R. Heinzelman, and H. Balakrishnan, "Negotiation-based protocols for disseminating information in wireless sensor networks," Wireless Networks, Volume: 8, pp. 169-185, 2002. 
[57] C. Intanagonwiwat, R. Govindan, and D. Estrin, "Directed diffusion: a scalable and robust communication paradigm for sensor networks," Proceedings of ACM MobiCom '00, Boston, MA, 2000, pp. 56-67.

[58] D. Braginsky and D. Estrin, "Rumor Routing Algorithm for Sensor Networks," in the Proceedings of the First Workshop on Sensor Networks and Applications (WSNA), Atlanta, GA, October 2002

[59] F. Ye, A. Chen, S. Liu, L. Zhang, "oA scalable solution to minimum cost forwarding in large sensor networks", Proceedings of the tenth International Conference on Computer Communications and Networks (ICCCN), pp. 304309, 2001.

[60] C. Schurgers and M.B. Srivastava, "Energy efficient routing in wireless sensor networks", in the MILCOM Proceedings on Communications for Network-Centric Operations: Creating the Information Force, McLean, VA, 2001.

[61] M. Chu, H. Haussecker, and F. Zhao, "Scalable Information-Driven Sensor Querying and Routing for ad hoc Heterogeneous Sensor Networks," The International Journal of High-Performance Computing Applications, Vol. 16, No. 3, August 2002.

[62] Y. Yao and J. Gehrke, "The cougar approach to in-network query processing in sensor networks", in SIGMOD Record, September 2002.

[63] N. Sadagopan et al., The ACQUIRE mechanism for efficient querying in sensor networks, in the Proceedings of the First International Workshop on Sensor Network Protocol and Applications, Anchorage, Alaska, May 2003.

[64] R. C. Shah and J. Rabaey, "Energy Aware Routing for Low Energy Ad Hoc Sensor Networks", IEEE Wireless Communications and Networking Conference (WCNC), March 17-21, 2002, Orlando, FL.

[65] W. Heinzelman, A. Chandrakasan and H. Balakrishnan, "Energy-Efficient Communication Protocol for Wireless Microsensor Networks," Proceedings of the 33rd Hawaii International Conference on System Sciences (HICSS '00), January 2000.

[66] S. Lindsey, C. Raghavendra, "PEGASIS: Power-Efficient Gathering in Sensor Information Systems", IEEE Aerospace Conference Proceedings, 2002, Vol. 3, 9-16 pp. 1125-1130.

[67] A. Manjeshwar and D. P. Agarwal, "TEEN: a routing protocol for enhanced efficiency in wireless sensor networks," In 1st International Workshop on Parallel and Distributed Computing Issues in Wireless Networks and Mobile Computing, April 2001.

[68] A. Manjeshwar and D. P. Agarwal, "APTEEN: A hybrid protocol for efficient routing and comprehensive information retrieval in wireless sensor networks," Parallel and Distributed Processing Symposium., Proceedings International, IPDPS 2002, pp. 195-202.

[69] V. Rodoplu and T. H. Meng," Minimum Energy Mobile Wireless Networks", IEEE Journal Selected Areas in Communications, vol. 17, no. 8, Aug. 1999, pp. 133344.

[70] L. Li, and J. Y. Halpern, "Minimum-Energy Mobile Wireless Networks Revisited," IEEE International Conference on Communications (ICC) 2001. Vol. 1, pp. 278-283.

[71] L. Subramanian and R. H. Katz, "An Architecture for Building Self Configurable Systems", in the Proceedings of IEEE/ACM Workshop on Mobile Ad Hoc Networking and Computing, Boston, MA, August 2000.

[72] Q. Fang, F. Zhao, and L. Guibas, "Lightweight Sensing and Communication Protocols for Target Enumeration and Aggregation", Proceedings of the 4th ACM international symposium on Mobile ad hoc networking and computing (MOBIHOC), 2003, pp. 165-176.

[73] Jamal N. Al-Karaki, Raza Ul-Mustafa, Ahmed E. Kamal, "Data Aggregation in Wireless Sensor Networks - Exact and Approximate Algorithms'", Proceedings of IEEE Workshop on High Performance Switching and Routing (HPSR) 2004, April 18-21, 2004, Phoenix, Arizona, USA.

[74] Q. Li and J. Aslam and D. Rus, "Hierarchical Power-aware Routing in Sensor Networks", In Proceedings of the DIMACS Workshop on Pervasive Networking, May, 2001.

[75] F. Ye, H. Luo, J. Cheng, S. Lu, L. Zhang, "A Two-tier data dissemination model for large-scale wireless sensor networks", proceedings of ACM/IEEE MOBICOM, 2002.

[76] N. Bulusu, J. Heidemann, D. Estrin, "GPS-less low-cost outdoor localization for very small devices", Technical report 00-729, Computer science department, University of Southern California, Apr. 2000

[77] A. Savvides, C-C Han, aind M. Srivastava, "Dynamic finegrained localization in Ad-Hoc networks of sensors," Proceedings of the Seventh ACM Annual International Conference on Mobile Computing and Networking (MobiCom), July 2001. pp. 166-179.

[78] S. Capkun, M. Hamdi, J. Hubaux,"GPS-free positioning in mobile ad-hoc networks", Proceedings of the 34th Annual Hawaii International Conference on System Sciences, 2001 pp. 3481-3490.

[79] Y. Xu, J. Heidemann, D. Estrin, "Geography-informed Energy Conservation for Ad-hoc Routing," In Proceedings of the Seventh Annual ACM/IEEE International Conference on Mobile Computing and Networking 2001, pp. 70-84.

[80] Y. Xu, J. Heidemann, D. Estrin, "Geography-informed Energy Conservation for Ad-hoc Routing," In Proceedings of the Seventh Annual ACM/IEEE International Conference on Mobile Computing and Networking 2001, pp. 70-84.

[81] Y. Yu, D. Estrin, and R. Govindan, "Geographical and Energy-Aware Routing: A Recursive Data Dissemination Protocol for Wireless Sensor Networks", UCLA Computer Science Department Technical Report, UCLACSD TR-010023, May 2001

[82] B. Karp and H. T. Kung, "GPSR: Greedy perimeter stateless routing for wireless sensor networks", in the Proceedings of the 6th Annual ACM/IEEE International Conference on Mobile Computing and Networking (MobiCom '00), Boston, MA, August 2000.

[83] I. Stojmenovic and X. Lin. "GEDIR: Loop-Free Location Based Routing in Wireless Networks", In International Conference on Parallel and Distributed Computing and Systems, Boston, MA, USA, Nov. 3-6, 1999.

[84] F. Kuhn, R. Wattenhofer, A. Zollinger, "Worst-Case optimal and average case efficient geometric ad-hoc routing", Proceedings of the 4th ACM International Conference on Mobile Computing and Networking, Pages: 267278, 2003

[85] Solihin, Yan (2016). fundamentals of parallel computer architecture. solihin books. pp. 390-392

[86] Abo-Zahhad, Mohammed, et al. "A centralized immuneVoronoi deployment algorithm for coverage maximization and energy conservation in mobile wireless sensor networks." Information Fusion 30 (2016): 36-51.

[87] Bhatia, Tarunpreet, et al. "A genetic algorithm based distance-aware routing protocol for wireless sensor networks." Computers \& Electrical Engineering (2016).

[88] Gupta, Suneet Kumar, Pratyay Kuila, and Prasanta K. Jana. "Genetic algorithm approach for k-coverage and $\mathrm{m}$ connected node placement in target based wireless sensor networks." Computers \& Electrical Engineering (2015). 
[89] Shankar, T., S. Shanmugavel, and A. Rajesh. "Hybrid HSA and PSO algorithm for energy efficient cluster head selection in wireless sensor networks." Swarm and Evolutionary Computation (2016).

[90] Ozdag, Recep, and Ali Karc1. "Probabilistic dynamic distribution of wireless sensor networks with improved distribution method based on electromagnetism-like algorithm." Measurement 79 (2016): 66-76.

[91] Zahedi, Zeynab Molay, et al. "Swarm intelligence based fuzzy routing protocol for clustered wireless sensor networks." Expert Systems with Applications 55 (2016): 313-328.

[92] Shokouhifar, Mohammad, and Ali Jalali. "A new evolutionary based application specific routing protocol for clustered wireless sensor networks." AEU-International Journal of Electronics and Communications 69.1 (2015): 432-441.

[93] Khalesian, Mina, and Mahmoud Reza Delavar. "Wireless sensors deployment optimization using a constrained Pareto-based multi-objective evolutionary approach." Engineering Applications of Artificial Intelligence 53 (2016): 126-139.

[94] Pal, Vipin, Girdhari Singh, and R. P. Yadav. "Cluster Head Selection Optimization Based on Genetic Algorithm to Prolong Lifetime of Wireless Sensor Networks." Procedia Computer Science 57 (2015): 1417-1423.

[95] Sun, Xuemei, et al. "Optimization deployment of wireless sensor networks based on culture-ant colony algorithm." Applied mathematics and computation 250 (2015): 58-70.

[96] Potthuri, Sweta, T. Shankar, and A. Rajesh. "Lifetime Improvement in Wireless Sensor Networks using Hybrid Differential Evolution and Simulated Annealing (DESA)." Ain Shams Engineering Journal (2016).

[97] Taherian, Mohsen, et al. "The Design of an Optimal and Secure Routing Model in Wireless Sensor Networks by Using PSO Algorithm." Procedia Computer Science 73 (2015): 468-473.

[98] Kuila, Pratyay, and Prasanta K. Jana. "A novel differential evolution based clustering algorithm for wireless sensor networks." Applied soft computing 25 (2014): 414-425.

[99] Kuila, Pratyay, and Prasanta K. Jana. "Energy efficient clustering and routing algorithms for wireless sensor networks: Particle swarm optimization approach." Engineering Applications of Artificial Intelligence 33 (2014): 127-140.

[100]Liu, Xuxun, and Desi He. "Ant colony optimization with greedy migration mechanism for node deployment in wireless sensor networks." Journal of Network and Computer Applications 39 (2014): 310-318.

[101] Lu, Yao, et al. "Construction of data aggregation tree for multi-objectives in wireless sensor networks through jump particle swarm optimization." Procedia Computer Science 35 (2014): 73-82.

[102]Gajjar, Sachin, Mohanchur Sarkar, and Kankar Dasgupta. "FAMACROW: Fuzzy and ant colony optimization based combined mac, routing, and unequal clustering cross-layer protocol for wireless sensor networks." Applied Soft Computing 43 (2016): 235-247.

[103]Zhang, Xin-Yuan, et al. "Kuhn-Munkres Parallel Genetic Algorithm for the Set Cover Problem and Its Application to Large-Scale Wireless Sensor Networks." (2015).

[104]Ye, Miao, et al. "A Hybrid Genetic Algorithm for the Minimum Exposure Path Problem of Wireless Sensor Networks Based on a Numerical Functional Extreme Model."
[105]Guo, Wenzhong, et al. "A PSO-optimized real-time faulttolerant task allocation algorithm in wireless sensor networks." IEEE Transactions on Parallel and Distributed Systems 26.12 (2015): 3236-3249.

[106]Rejina Parvin, J., and C. Vasanthanayaki. "Particle Swarm Optimization-Based Clustering by Preventing Residual Nodes in Wireless Sensor Networks." IEEE Sensors Journal 15.8 (2015): 4264-4274

[107]Murugeswari, R., S. Radhakrishnan, and D. Devaraj. "A multi-objective evolutionary algorithm based QoS routing in wireless mesh networks." Applied Soft Computing 40 (2016): 517-525.

[108]Lanza-Gutierrez, Jose M., and Juan A. Gomez-Pulido. "Assuming multiobjective metaheuristics to solve a threeobjective optimisation problem for Relay Node deployment in Wireless Sensor Networks." Applied Soft Computing 30 (2015): 675-687.

[109]WANG, Ya-li, et al. "Improved ant colony-based multiconstrained QoS energy-saving routing and throughput optimization in wireless Ad-hoc networks." The Journal of China Universities of Posts and Telecommunications 21.1 (2014): 43-59.

[110]Qiao, Dapeng, and Grantham KH Pang. "Evolutionary approach on connectivity-based sensor network localization." Applied Soft Computing 22 (2014): 36-46.

[111]Adnan, Md Akhtaruzzaman, et al. "Bio-mimic optimization strategies in wireless sensor networks: A survey." Sensors 14.1 (2013): 299-345.

[112]Akyildiz, Ian F., et al. "Wireless sensor networks: a survey." Computer networks 38.4 (2002): 393-422.

[113]Yick, Jennifer, Biswanath Mukherjee, and Dipak Ghosal. "Wireless sensor network survey." Computer networks 52.12 (2008): 2292-2330.

[114]Goswami, P., Yan, Z., Mukherjee, A., Yang, L., Routray, S., \& Palai, G. (2019). An energy efficient clustering using firefly and HML for optical wireless sensor network. Optik, $182,181-185$.

[115]Yan, Z., Goswami, P., Mukherjee, A., Yang, L., Routray, S., \& Palai, G. (2019). Low-energy PSO-based node positioning in optical wireless sensor networks. Optik, 181, 378-382.

[116]Singh, Karishma, Karan Singh, and Ahmed Aziz. "Congestion control in wireless sensor networks by hybrid multi-objective optimization algorithm." Computer Networks 138 (2018): 90-107.

[117]Sun, Z., Wei, M., Zhang, Z., \& Qu, G. (2019). Secure Routing Protocol based on Multi-objective Ant-colonyoptimization for wireless sensor networks. Applied Soft Computing. 